\title{
En Fazla İki Adet Komşuluk Özdeğeri -1,0 ya da 1,0'dan Farklı Olan Graflar
}

\author{
Hatice TOPCU*1 1 \\ ${ }^{1}$ Nevşehir Hacı Bektaş Veli Üniversitesi, Fen Edebiyat Fakültesi, Matematik Bölümü, 50300, Nevşehir
}

(Alınış / Received: 15.12.2018, Kabul / Accepted: 30.05.2020, Online Yayınlanma / Published Online: 20.08.2020)

\author{
Anahtar Kelimeler \\ Kospektral graflar, \\ Spektral karakterizasyon, \\ Çok parçalı tam graf
}

Özet: Bir grafin komşuluk matrisinin özdeğerleri, komşuluk spektrumunu oluşturur. Bu çalışmada, en fazla iki adet komşuluk özdeğeri $-1,0$ ya da 1,0'dan farklı olan tüm grafların oluşturduğu kümeler ile ilgili bazı sonuçlar sınıflandırma yapılmak suretiyle bir araya getirilmiștir. Bir grafta izole bir nokta, bu grafın komşuluk spektrumunda sadece bir adet sıfır özdeğerin yer almasına yol açacaktır. Bu sebepten dolayı, öncelikle izole nokta içermeyen grafların olușturduğu kümeler incelenerek belirlenmeye çalışılmıştır. Daha sonra ise izole noktalar da bu kümelere dâhil edilerek, incelenen kümeler genişletilmiştir. Bu sınıflandırma, genel olarak çok parçalı tam grafları ve izole noktaları içermektedir. Dolayısıyla burada verilen grafların komşuluk spektrumlarına göre belirlenebilir olup olmadıklarına da yine bu çalışmada değinilmiştir.

\section{Graphs with All but Two Eigenvalues Equal to -1,0 or 1,0}

\section{Keywords}

Cospectral graphs, Spectral characterization, Complete multipartite graphs

\begin{abstract}
Adjacency spectrum of a graph, consists of the eigenvalues of its adjacency matrix. In this note, we compile some results (by making a classification) about the sets of all graphs that contain at most two adjacency eigenvalues different from -1,0 or 1,0. For a given graph, an isolated vertex makes a zero eigenvalue in its adjacency spectrum. Thus, firstly the sets which contains graphs without isolated vertices are investigated. Then, these sets are extended with isolated vertices. This classification includes disjoint unions of complete multipartite graphs and isolated vertices. Hence, we also mention that graphs given in here are determined by their adjacency spectrum (shortly DAS) or nonDAS.
\end{abstract}

\section{Giriş ve Önbilgiler}

Bir G grafi, boștan farklı ve sonlu V(G) noktalar kümesi ile $E(G)$ kenarlar kümesi tarafından teşkil edilir ve $G=(V(G), E(G))$ biçiminde gösterilir. Eğer bir grafta katlı kenar (aynı iki nokta arasında yer alan birden fazla kenar, multiple edge) ve ilmek (bir noktayı yine kendine bağlayan kenar, loop) bulunmuyorsa, bu grafa basit graf (simple graph) denir. Bu çalışmada yer alan tüm graflar basittir ve kenarları yönlendirilmemiştir. Bir $v \in V(G)$ noktasının derecesi (degree of a vertex) kendisine komşu olan noktaların sayısıdır. Eğer bir noktanın derecesi sıfıra eşit ise yani $V(G)$ kümesindeki noktaların hiçbirine komşu değilse bu noktaya izole nokta (isolated vertex) denir. $V^{\prime} \subseteq V(G)$ ve $E^{\prime} \subseteq E(G)$ olacak şekilde $V^{\prime}$ ve $E^{\prime}$ kümeleri için $G^{\prime}=\left(V^{\prime}, E^{\prime}\right)$ grafina $G$ grafinın bir alt grafi (subgraph) denir. Bir grafta bazı noktaların ve bu noktalara değen tüm kenarların silinmesiyle oluşan bir alt grafa ise indirgenmiş alt graf (induced subgraph) denir. Bir $G$ grafi tarafından indirgenmiş alt graf olarak içerilmesi mümkün olmayan bir grafa ise $G$ grafi için yasaklanmış alt graf (forbidden subgraph) denir. Herhangi iki noktası arasında daima en az bir yol bulunabilen bir grafa bağlantılı graf (connected graph) denir. Bağlantılı olmayan bir grafa ise bağlantısız graf (disconnected graph) denir. Bir $G$ grafının maksimal bağlantılı her bir alt grafına $G$ grafının bir bileşeni (component) denir. Verilen iki $G$ ve $H$ grafının ayrık birleşimi (disjoint union) $G \cup ̊ H$ ile $G$ grafının $m$ adet kopyasının ayrık birleşimi ise $m G$ ile gösterilir. $n$ adet noktaya sahip tam graf (complete graph) $K_{n}$ ile, yol graf (path graph) ise $P_{n}$ ile gösterilir. $V(G)$ noktalar kümesinin bir parçalanışı $p_{1}, \ldots, p_{k}$ olsun. Eğer aynı parçada yer alan noktalar arasında kesinlikle bir kenar bulunmuyor ve farklı parçalarda yer alan noktalar arasında daima bir kenar bulunuyor ise bu grafa çok parçalı tam graf (complete multipartite graph) denir ve $K_{p_{1}, \ldots, p_{k}}$ ile gösterilir. $k=2$ ise bu grafa özel olarak iki parçalı tam graf (complete bipartite graph) denir. 
Graflar matrisler yardımıyla temsil edilebilir. $G=(V(G), E(G))$ grafi $n$ adet noktaya sahip bir graf ve $i, j \in V(G)$ olsun. $i$ ve $j$ noktaları arasında bir kenar var ise $a_{i j}=1$; yok ise $a_{i j}=0$ biçiminde tanımlanan $A(G)=\left[a_{i j}\right]_{n \times n}$ matrisine $G$ grafının komşuluk matrisi (adjacency matrix) denir. $\mathrm{Bu}$ matrisin özdeğerlerine $G$ grafinın komşuluk özdeğerleri (adjacency eigenvalues), ya da kısaca özdeğerleri denir. Komşuluk özdeğerlerinin cebirsel katları ile birlikte oluşturduğu kümeye ise $G$ grafinın komşuluk spektrumu (adjacency spectrum) ya da kisaca spektrumu denir. $A(G)$ tamsayı bileșenli ve simetrik bir matris olduğundan, $G$ grafının komşuluk özdeğerleri $\lambda_{1}(G) \geq \lambda_{2}(G) \geq \cdots \geq \lambda_{n}(G)$ biçiminde gösterilebilir. Herhangi iki graf aynı komşuluk özdeğerlerine sahip ise, bu graflara komşuluk özdeğerlerine göre kospektral graflar (cospectral graphs) denir. Aynı sayıda noktaya ve aynı sayıda kenara sahip $G$ ve $H$ grafları verilsin. $V(G)$ ve $V(H)$ nokta kümeleri arasında noktaların birbirine komşuluğunu koruyan, birebir ve örten bir $f$ dönüşümü bulunabiliyorsa, $G$ ve $H$ graflarına izomorf graflar (isomorphic graphs) denir. Bu durum $G \cong H$ biçiminde gösterilir. İzomorf grafların komşuluk spektrumlarının aynı olduğu açıktır. Fakat bu durumun tersi her zaman doğru değildir[1]. Eğer bir $G$ grafı ile aynı komşuluk spektrumuna sahip olan herhangi bir graf kesinlikle $G$ grafina izomorf oluyorsa, $G$ ye komşuluk spektrumuna göre belirlenebilir bir graf (kısaca DAS; determined by adjacency spectrum) denir. Bu çok iyi bilinen problem hakkında daha detaylı bilgi için [1-3] kaynaklarına bakılabilir.

Wang, Belardo, Huang ve Borovicanin, $F_{k}$ friendship grafının komşuluk spektrumuna göre belirlenebilir bir graf olduğunu iddia etmişlerdir [5]. Bu konjektürden alınan motivasyon ve daha farklı bir bakış açısı ile Cioaba, Haemers, Vermette ve Wong en fazla iki adet komşuluk özdeğeri $\mp 1$ den farklı olan tüm grafları sinıflandırmışlardır [10]. Daha sonrasinda aynı yazarlar tarafindan en fazla iki adet komşuluk özdeğeri -2 ve 0 dan farklı olan tüm graflar sinıflandırılmıştır [9]. Yakın zamanda ise Lima, Mohammedian ve Oliveira en fazla iki adet komşuluk özdeğeri [-1,1] aralığına düşen iki parçalı olmayan tüm grafları belirlemişlerdir [7]. Bu çalışmada ise, en fazla iki adet komşuluk özdeğeri $-1,0$ ya da 1,0 dan farklı olan tüm graflar ile ilgili sonuçlar verilmiştir. En fazla iki adet özdeğeri (cebirsel katları da dâhil edilerek) $\{-1,0\}$ ya da $\{1,0\}$ dan farklı olan tüm grafların sinıflandırmaları yapılmıştır. $\mathrm{Bu}$ sınıflandırmalarda yer alan grafların komşuluk spektrumlarına göre belirlenebilir olup olmadıklarına da değinilmiștir.

Sonraki bölümlerde kullanılacak bazı bilgilere de bu kısımda yer verilmiştir.

Lemma 1.1. [1] $n$ adet noktaya sahip bir $G$ grafinın komşuluk özdeğerleri $\lambda_{1}(G) \geq \lambda_{2}(G) \geq \cdots \geq \lambda_{n}(G)$ ve $G$ nin indirgenmiş $m$ noktalı bir $H$ altgrafının komşuluk özdeğerleri $\lambda_{1}(H) \geq \lambda_{2}(H) \geq \cdots \geq \lambda_{m}(H)$ olsun. Buna göre aşağıdaki eşitsizlik $i=1, \ldots, m$ için daima sağlanır.

$$
\lambda_{i}(G) \geq \lambda_{i}(H) \geq \lambda_{n-m+i}(G)
$$

Lemma 1.2. [2,4] Bir $G$ grafının negatif komşuluk özdeğerlerinin sayısı $\rho_{-}$ve $k=1+\rho_{-}$olsun. $G$ grafının kesin olarak yalnızca bir adet pozitif komşuluk özdeğerine sahip olması için gerek ve yeter koşul izole olmayan tüm noktalarının $k$-parçalı tam graf oluşturmasıdır.

Lemma 1.3. [8] Sadece 1 adet nokta içeren parçaların sayısı $k$ ve $k \geq 2$ olmak üzere; $K_{1, \ldots, 1, m}$ grafı komşuluk spektrumuna göre belirlenebilir bir graftır.

Lemma 1.4. [1,2] $n \times n$ tipindeki $A$ ve $B$ matrisleri için aşağıdaki ifadeler denktir.

(i) $A$ ve $B$ aynı spektruma sahiptir.

(ii) $A$ ve $B$ aynı karakteristik polinoma sahiptir.

(iii) $i=1, \ldots, n$ olmak üzere $i z\left(A^{i}\right)=i z\left(B^{i}\right)$ dir.

Lemma 1.5. [4] $s$ ve $t$ pozitif tamsaylar olsun. İki parçalı tam $K_{s, t}$ grafının komşuluk spektrumuna göre belirlenebilir olması için gerek ve yeter koşul $s+t$ toplamının en küçük değeri alması koşuluyla $n=s t$ olacak biçimde $s$ ve $t$ çarpanlarına ayrılabilmesidir.

\section{En Fazla İki Adet Özdeğeri -1 ve 0 dan Farklı Olan Graflar}

En fazla iki adet özdeğeri (cebirsel katları da dahil olmak üzere) -1 ve 0 dan farklı olan tüm grafların kümesini $S$ ile gösterelim. İzole bir nokta, bir grafın komşuluk spektrumunda sadece bir adet sıfır özdeğerin yer almasına yol açacağından, aşağıdaki lemmada izole nokta içermeyen $S^{\prime} \subseteq S$ kümesi incelenecektir.

Lemma 2.1. Eğer $G \in S^{\prime}$ ise $G$ grafı aşağıdaki graflardan birine kesinlikle izomorftur. $p, q, k, l, m, n$ pozitif tamsayıları için,

(i) $K_{p} \stackrel{\mathrm{U}}{ } K_{q}$ öyle ki komşuluk spektrumu $\{p-1, q-1$, $\left.-1^{p+q-2}\right\}$

(ii) $K_{l, n}$ öyle ki komşuluk spektrumu $\left\{\mp \sqrt{l n}, 0^{l+n-2}\right\}$

(iii) Bir adet nokta içeren parçaların sayısı k olmak üzere; $K_{1, \ldots, 1, m}$ öyle ki komşuluk spektrumu $\left\{\frac{k-1 \pm \sqrt{(k-1)^{2}-4 k m}}{2},-1^{k-1}, 0^{m-1}\right\}$

İspat: Eğer $G \in S^{\prime}$ ise $a, b \in \mathbb{R}-\{-1,0\}$ olmak üzere $\operatorname{spec}(G)=\left\{-1^{f}, 0^{g}, a, b\right\}$ biçimindedir. Burada $f$ ve $g$ sırasıyla -1 ve 0 özdeğerlerinin cebirsel katlarıdır. $G$ en az bir pozitif komşuluk özdeğerine sahip olmak zorunda olduğundan, $a \geq b>0$ ya da $a>0>b$ olmalıdır. 
$a \geq b>0$ iken inceleyelim. Bu durumda $G$ grafının en küçük komşuluk özdeğeri -1 e eşit olacaktır. 3 noktalı yol graf için $\lambda_{3}\left(P_{3}\right) \cong-1.42$ olduğu için, Lemma 1.1'den $G$ grafının herhangi bir bileșeni için $P_{3}$ grafi yasaklanmış bir alt graf olur. Dolayısıyla $G$ grafının herhangi bir bileşenindeki herhangi 3 adet nokta birbirine komşu olmak zorundadır. Bu da $G$ nin tüm bileşenlerinin birer tam graf olmasını gerektirir. Aynı zamanda $G$ de sadece 2 adet pozitif özdeğer bulunduğundan, $p=a+1, q=b+1, f=p+q-$ 2 ve $g=0$ olmak üzere $G \cong K_{p} \stackrel{\mathrm{U}}{ } K_{q}$ dir. Böylece $\operatorname{spec}(G)=\left\{p-1, q-1,-1^{p+q-2}\right\}$ olur.

Şimdi de $a>0>b$ iken inceleyelim. Lemma 2.2'den, $G$ çok parçalı tam graftır. Eğer $G$ iki parçalı tam graf ise $-b=a=\sqrt{l n}, f=0$ ve $g=l+n-2$ olmak üzere $\operatorname{spec}(G)=\left\{\mp \sqrt{l n}, 0^{l+n-2}\right\}$ olur. $c \geq 3$ için, $G$ cparçalı tam graf olsun. $K_{1,2,2}$ grafinın negatif özdeğerleri $\{-2,-1.23607\}$ olduğundan bu graf $G$ grafının Lemma 1.1'e göre yasaklanmış bir alt grafıdır. Böylece $G$ grafının 1den fazla noktaya sahip en fazla 1 adet parça içerebileceğini söyleriz. Buradan, bir adet nokta içeren parçaların sayısı $\mathrm{k}$ olmak üzere, $G \cong K_{1, \ldots, 1, m}$ olur. $\mathrm{Bu}$ durumda $\operatorname{spec}(G)=\left\{\frac{k-1 \pm \sqrt{(k-1)^{2}-4 k m}}{2},-1^{k-1}, 0^{m-1}\right\} \quad$ elde edilir öyle ki burada $a=\frac{k-1+\sqrt{(k-1)^{2}-4 k m}}{2}, \quad b=$ $\frac{k-1-\sqrt{(k-1)^{2}-4 k m}}{2}, c=k+1, f=k-1$ ve $g=m-1$ dir.

Aşağıdaki sonuç yardımıyla $S$ kümesi artık belirlenebilir.

Sonuç 2.2. $\alpha \in \mathbb{Z}^{+} \cup\{0\}$ olsun. 0 zaman $S=$ $\left\{G \mathrm{U}^{\prime} \alpha K_{1}: G \in S^{\prime}\right\}$ olur.

Lemma 1.3 ve Lemma 1.5 yardımıyla aşağıdaki sonuçta açlktır.

Sonuç 2.3. $G \in S$ olsun.

(i) Eğer $G$ grafı iki parçalı tam bir grafı bileşen olarak içermiyorsa o zaman komşuluk spektrumuna göre belirlenebilir bir graftır.

(ii) $G$ grafının bir bileșeni $K_{l, n}$ olsun. 0 zaman $G$ grafının komşuluk spektrumuna göre belirlenebilir bir graf olması için gerek ve yeter koşul $l+n$ toplamının en küçük değeri alması koşuluyla $x=\ln$ olacak biçimde $l$ ve $n$ çarpanlarına ayrılabilmesidir.

\section{En Fazla İki Adet Özdeğeri 1 ve 0 dan Farklı Olan Graflar}

En fazla iki adet özdeğeri (cebirsel katları da dahil olmak üzere) 1 ve 0 dan farklı olan tüm grafların kümesini $H$ ile gösterelim. İzole bir nokta, bir grafın komşuluk spektrumunda sadece bir adet sıfir özdeğerin yer almasına yol açacağından, aşağıdaki lemmada izole nokta içermeyen $H^{\prime} \subseteq H$ kümesi incelenecektir.
Lemma 3.1. Eğer $G \in H^{\prime}$ ise $G$ grafı aşağıdaki graflardan birine kesinlikle izomorftur. $l, n$ pozitif tamsayıları için,

(i) $\alpha \in\{1,2\}$ olmak üzere $\alpha K_{2}$ öyle ki komşuluk spektrumu $\left\{-1^{\alpha}, 1^{\alpha}\right\}$

(ii) $K_{l, n}$ öyle ki komşuluk spektrumu $\left\{\mp \sqrt{l n}, 0^{l+n-2}\right\}$

İspat: $G \in H^{\prime}$ olsun. 0 zaman $\operatorname{spec}(G)=\left\{1^{f}, 0^{g}, a, b\right\}$ olacak biçimde $a, b \in \mathbb{R}-\{1,0\}$ vardır öyle ki burada $f$ ve $g$ sirasiyla 1 ve 0 özdeğerlerinin cebirsel katlarıdır. Buna göre, $a$ ve $b$ sayıları için üç durum söz konusudur; $0<b \leq a, b \leq a<0$ ya da $b<0<a$. Lemma 1.4'ten,

$$
i z(A)=\sum_{i=1}^{n} \lambda_{i}(G)=0
$$

elde edilir. Buradan,

$$
a+b+f=0
$$

olur. Dolayısıyla $a$ ve $b$ sayılarının aynı anda pozitif olması mümkün değildir.

$b \leq a<0$ iken inceleyelim. Bu durumda, $G$ grafını pozitif özdeğerlerinin hepsi 1 dir. $\mathrm{Bu}$ da $G$ nin tüm bileşenlerinin $K_{2}$ grafına izomorf olması demektir. En fazla iki adet özdeğeri 1 ve 0 dan farklı olduğundan, $G$ grafı $K_{2}\left(=K_{1,1}\right)$ ya da $K_{2} \mathrm{U} K_{2}\left(=2 K_{2}\right)$ grafına izomorf olur.

$b<0<a$ iken inceleyelim. Bu durumda $\mathrm{G}$ grafinın yalnızca bir adet negatif özdeğeri vardır. $K_{3}$ tam grafı ve $P_{4}$ yol grafı iki adet negatif özdeğere sahip olduklarından Lemma 1.1'e göre G grafı için yasaklanmış alt graf olurlar. Böylece çizilebilecek izole nokta içermeyen graf yalnızca çok parçalı tam graf olduğundan, G grafı çok parçalı bir tam graftır. Lemma 1.2'ye göre çok parçalı bir tam graf yalnızca bir adet pozitif özdeğer içerebileceğinden $\mathrm{f}=0$ elde edilir ve aynı zamanda $G$ grafının yalnızca bir adet negatif özdeğeri bulunduğundan G iki parçalı bir tam graf olacaktır.

Aşağıdaki sonuç yardımıyla $H$ kümesi $\operatorname{artık}$ belirlenebilir.

Sonuç 3.2. $\beta \in \mathbb{Z}^{+} \cup\{0\}$ olsun. 0 zaman $H=$ $\left\{G \mathrm{U} \beta K_{1}: G \in H^{\prime}\right\}$ olur.

Sonuç 2.3 e benzer şekilde $H$ kümesi için de aşağıdaki sonuç elde edilir.

Sonuç 3.3. $G \in H$ olsun.

(i) Eğer $G$ grafı iki parçalı tam bir grafı bileșen olarak içermiyorsa o zaman komşuluk spektrumuna göre belirlenebilir bir graftır.

(ii) $G$ grafinın bir bileșeni $K_{l, n}$ olsun. 0 zaman $G$ grafının komşuluk spektrumuna göre belirlenebilir 
bir graf olması için gerek ve yeter koşul $l+n$ toplamının en küçük değeri alması koşuluyla $x=\ln$ olacak biçimde $l$ ve $n$ çarpanlarına ayrılabilmesidir.

\section{En Fazla İki Adet Özdeğeri \pm 1 ve 0 dan Farklı Olan Graflar}

En fazla iki adet özdeğeri (cebirsel katları da dahil olmak üzere) \pm 1 ve 0 dan farklı olan ve izole nokta içermeyen tüm grafların kümesini $W$ ile gösterelim. $W^{\prime} \subseteq W$ ile de \pm 1 ve 0 dan farklı olan özdeğerleri aynı işarete sahip olan grafların kümesini gösterelim. Buna göre aşağıdaki lemmada $W^{\prime}$ kümesi incelenecektir.

Lemma 4.1. Eğer $G \in W^{\prime}$ ise $G$ grafı aşağıdaki graflardan birine kesinlikle izomorftur. $l, n$ pozitif tamsayıları için,

(i) $\alpha K_{2}$ öyle ki komşuluk spektrumu $\left\{-1^{\alpha}, 1^{\alpha}\right\}$

(ii) $K_{p} \mathrm{U} K_{q}$ öyle ki komşuluk spektrumu $\{p-1, q-1$, $\left.-1^{p+q-2}\right\}$

İspat: $\mathrm{G}$ grafinın spektrumunu $\left\{-1^{f}, 1^{g}, 0^{h}, a, b\right\}$ biçiminde gösterelim. Burada $G \in W^{\prime}$ olduğundan, a ve $b$ aynı anda pozitif ya da aynı anda negatiftir. Her ikisi de pozitif ise $G$ nin en küçük özdeğeri -1 olacaktır. Bu da G nin herhangi bir 3 noktalı alt grafının tam graf olduğunu dolayısıyla da G nin olası bileșenlerinin birer tam graf olduğunu gösterir. Eğer a ve b nin her ikisi de negatif ise G grafının en büyük özdeğeri 1 olacaktır. Bu da G grafının bileșenlerinin yalnızca $K_{2}$ lerden oluştuğunu gösterir.

Sonuç 4.1. $G \in W^{\prime}$ olsun. Buna göre $G$ grafı komşuluk spektrumuna göre belirlenebilir bir graftır.

\section{Sonuç ve Öneriler}

Bu çalışmada en fazla iki adet özdeğeri $-1,0$ ya da 1,0 'dan farklı olan grafların sinıflandırılması ve komşuluk spektrumlarına göre belirlenebilir olup olmadıkları üzerinde durulmuştur. Literatürde de en fazla iki adet özdeğer baz alınarak yapılmış çalışmalar mevcuttur $[7,9,10]$. Bu çalışmaların üç ya da daha fazla sayıda özdeğer baz alınarak yapılması, mevcut sınıflandırmaların daha geniş bir bakış açısıyla yapılabilmesine imkan tanıyacaktır. Aynı zamanda da daha geniş kümeler elde edilebileceği açıtır. Bu kümelerin spektrumlarına göre belirlenebilir olup olmadıklarının incelenmesi ise literatüre büyük katkı sağlayacaktır. Dolayısıyla, "En fazla 3 adet özdeğeri 1,0'dan farklı olan grafların sinıflandırılıp spektrumlarına göre belirlenebilir olup olmadıklarının incelenmesi" ve "En fazla 3 adet özdeğeri -1,0'dan farklı olan grafların sınıflandırılıp spektrumlarına göre belirlenebilir olup olmadıklarının incelenmesi" öncelikle incelenebilecek birer açık problemdir.

\section{Teşekkür}

Bu çalışma TÜBİTAK-ARDEB 117F489 no'lu proje kapsamında desteklenmiş ve üretilmiştir.

\section{Kaynakça}

[1] van Dam, E.R., Haemers, W.H. 2003. Which graphs are determined by their spectrum?. Linear Algebra and its Applications,373,241-272.

[2] Cvetkovic, D., Doob, M., Sachs, H. 1982. Spectra of graphs. Academic Press, 22s, 156s,New York.

[3] van Dam, E.R., Haemers, W.H. 2009. Developments on spectral characterizations of graphs. Discrete Mathematics, 309(3), 576-586.

[4] Ma, H., Ren, H. 2010. On the spectral characterization of the union of complete multipartite graph and some isolated vertices. Discrete Mathematics, 310, 3648-3652.

[5] Wang, J.F., Belardo, F., Huang, Q.X., Borovicanin, B. 2010. On the two largest Q-eigenvalues of graphs. Discrete Mathematics, 310, 2858-2866.

[6] Smith, J.H. 1970. Some properties of the spectrum of a graph. Combinatorial structures and their applications, Gordon and Breach, New York, 403406.

[7] de Lima, L.S., Mohammedian, A., Oliveira, C.S. 2017. The non-bipartite graphs with all but two eigenvalues in $[-1,1]$. Linear and Multilinear Algebra, 65(3), 526-544.

[8] Camara, M., Haemers, W.H. 2014. Spectral characterization of almost complete graphs. Discrete Applied Mathematics, 176, 19-23.

[9] Cioaba, S.M., Haemers, W.H., Vermette, J.D. 2017. The graphs with all but two eigenvalues equal to 2 or 0. Designs, Codes and Cryptography, 84, 153163.

[10] Cioaba, S.M., Haemers, W.H., Vermette, J.D., Wong, W. 2015. The graphs with all but two eigenvalues equal to \pm 1 . Journal of Algebraic Combinatorics, 41, 887-897.

[11] Haemers, W.H., Liu X., Zhang, Y. 2008. Spectral characterizations of lolipop graphs. Linear Algebra and its Applications, 428(11-12), 24152423. 